BANCA D'ITALIA

E U ROS I S T E M A

Questioni di Economia e Finanza

(Occasional Papers)

Indicators of uncertainty:

a brief user's guide

by Luca Rossi 

13 BANCA D'ITALIA

E U ROS I S T E M A

\section{Questioni di Economia e Finanza}

(Occasional Papers)

Indicators of uncertainty:

a brief user's guide

by Luca Rossi

Number 564 - June 2020 
The series Occasional Papers presents studies and documents on issues pertaining to the institutional tasks of the Bank of Italy and the Eurosystem. The Occasional Papers appear alongside the Working Papers series which are specifically aimed at providing original contributions to economic research.

The Occasional Papers include studies conducted within the Bank of Italy, sometimes in cooperation with the Eurosystem or other institutions. The views expressed in the studies are those of the authors and do not involve the responsibility of the institutions to which they belong.

The series is available online at www.bancaditalia.it.

ISSN $1972-6627$ (print)

ISSN 1972-6643 (online)

Printed by the Printing and Publishing Division of the Bank of Italy 


\title{
INDICATORS OF UNCERTAINTY: A BRIEF USER'S GUIDE
}

\author{
by Luca Rossi*
}

\begin{abstract}
This work examines the benefits and risks of using available classes of uncertainty indexes for policy purposes, clustered in three broad categories: survey-based, model-based, and news-based. In both policy discussions and the academic literature newsbased indexes are the ones that have recently gained the most attention. We argue that the reasons behind this are their intuitiveness, transparency and real-time characteristics. The main trouble with these indexes, as they are constructed today, is their noisiness. We then suggest that, for policy purposes, it would be better to disregard very high frequency movements in the series. Finally, we highlight that well-developed probabilistic surveys still represent a hard-to-beat benchmark when one is interested in uncertainty concerning specific variables as opposed to more abstract concepts such as Economic Policy Uncertainty.
\end{abstract}

JEL Classification: E60, H30, H68.

Keywords: uncertainty, filtering, economic surveys, news.

DOI: $10.32057 / 0$. QEF.2020.564

\section{Contents}

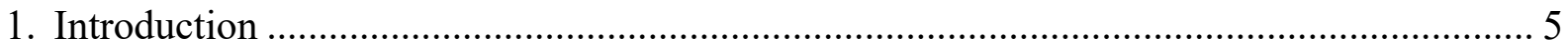

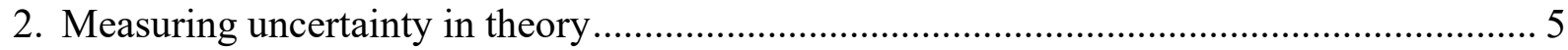

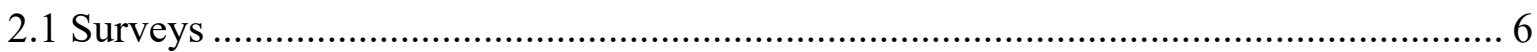

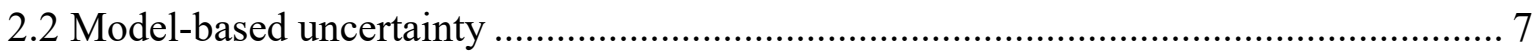

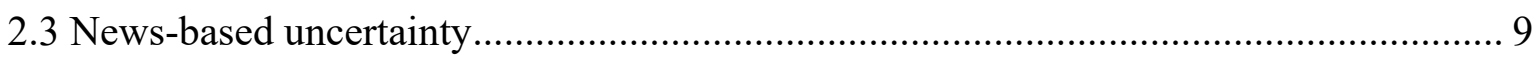

3. Measuring uncertainty in practice: the most popular indexes ........................................ 10

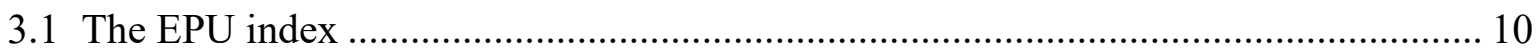

3.2 The relationship between different uncertainty measures ....................................... 14

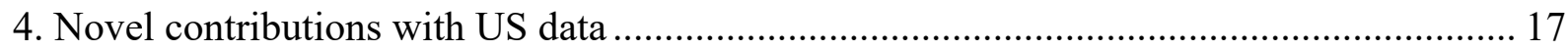

4.1 Atlanta Fed - Chicago Booth - Stanford University Survey of Business Uncertainty ... 17

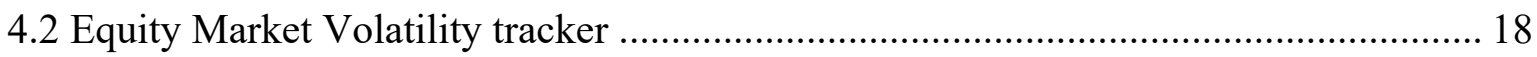

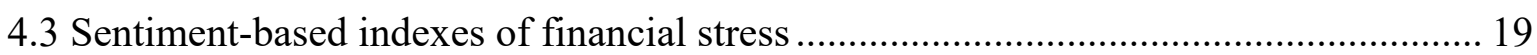

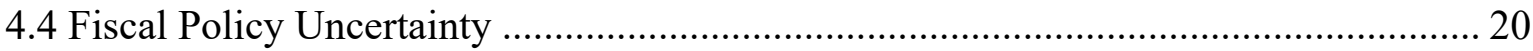

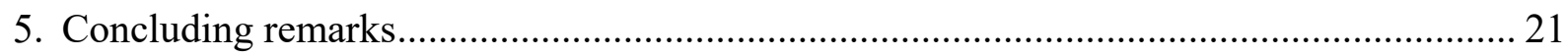

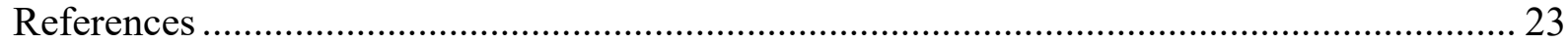

\footnotetext{
*Bank of Italy, Economic Research and International Relations.
} 



\section{Introduction}

Uncertainty is a multidimensional and highly nonlinear function of a variety of factors, and it would be wrong to simply talk about "uncertainty" as if it was a clearly defined concept. Different cuts of this function might tell completely different stories, and researchers have focused each time on particular types of uncertainty. As a result, it would be futile to attempt surveying all the uncertainty measures proposed so far in the literature. Moreover, the literature on uncertainty measures continues to expand rapidly, and a note that would only list the available contributions would soon become obsolete.

Our aim has a broader scope. First, we provide an overview of the main tools currently available to retrieve estimates of uncertainty. Second, we explain some practical details about them and their inter-relationships. Given the wealth of indicators, we have no ambition to be exhaustive, whereas we think that selected comments on a few of them will help the reader to reach a deeper understanding of the main properties of methodologically similar uncertainty indexes. Third, we discuss some new contributions, such as the new Atlanta Fed - Chicago Booth - Stanford University Survey of Business Uncertainty, a news-based Equity Volatility Tracker, sentiment indexes, and a novel Fiscal Policy Uncertainty index (some of them are still work in progress).

A comprehensive literature review on uncertainty measures can be found in Bloom (2014). While we refer to many of those contributions, along with more recent ones, in our analysis we will not delve into the details of each uncertainty index (the interested reader may refer directly to the cited papers for a deeper understanding of the various measures); rather, we will discuss some specific issues which may have been somewhat overlooked in the literature. Finally, in this paper we will not discuss the empirical research on the effects of uncertainty on economic activity.

\section{Measuring uncertainty in theory}

There are various ways in which uncertainty has been measured in the literature; each has its pros and cons, and some are superior to others depending on the particular application. However, the best options are not always available, meaning that at times researchers have had no alternative but to choose second bests. In this section we will mainly focus on the conceptual features and differences between the methods, whereas Section 3 will explore a selected set of indexes. 


\subsection{Surveys}

In cases where the researcher is interested in uncertainty surrounding a very specific variable, and if surveys exist that ask the probability distributions over the future evolution of that variable, then (assuming the forecasters have no incentives to deliver biased forecasts) surveys can yield the cleanest measure of uncertainty. The Philadelphia Fed Survey of Professional Forecasters (launched in 1968) and the ECB Survey of Professional Forecasters (launched in 1999) are paramount examples of probabilistic surveys.

Various measures of uncertainty can be retrieved from surveys. Following Giordani and Söderlind (2003), let respondent $i$ 's point forecast and the standard deviation surrounding it be denoted by $\mu_{i}$ and $\sigma_{i}$ respectively. Then, one can define $\mathbb{E}\left(\sigma_{i}^{2}\right)$ (average of variances) as the average individual uncertainty, or (as Giordani and Söderlind (2003) explain) "[...] the uncertainty a reader of forecasts faces if he randomly picks (and trusts) one of the point forecasts". Being the subjective uncertainty of the representative agent, average individual uncertainty theoretically is the most appealing real time survey-based measure of uncertainty.

Moreover, one can define aggregate uncertainty as:

$$
\mathbb{V}_{A}(y)=\mathbb{E}\left(\sigma_{i}^{2}\right)+\mathbb{V}\left(\mu_{i}\right),
$$

where $y$ is the random variable of interest (e.g. one-year-ahead inflation rate) and $\mathbb{V}\left(\mu_{i}\right)$ (variance of averages) is commonly referred to as disagreement. Even though aggregate uncertainty lacks a clear interpretation, it is nevertheless reported both in the Philadelphia Fed and the ECB Survey of Professional Forecasters.

The emphasis above on the real time characteristics acknowledges the possibility that the researcher might be willing to use ex-post information (i.e. realizations of the data) to retrieve additional measures of uncertainty. This is indeed discussed in Rossi B. et al. (2019), which is the first paper to provide both ex-ante and ex-post measures of uncertainty. Further examples are Rossi B. and Sekhposyan (2015) and Rossi B. and Sekhposyan (2017), where realized forecast errors are used to develop different uncertainty measures.

Disagreement has also been a widely used metric for uncertainty. The reason for this is that not all surveys provide density forecasts, meaning that the only measure of dispersion that can be retrieved is the cross-sectional variance of forecasters' central scenarios. This is true for the surveys provided by Consensus Economics, which ask forecasters only point forecasts. Nevertheless, using disagreement as an index for uncertainty has less theoretical appeal than average individual uncertainty. A very simple theoretical support for using disagreement as a proxy for uncertainty has been provided by Bachmann et al. 
(2013), who find that "[...] if firms receive signals about future conditions and those signals are neither perfectly informative nor perfectly uninformative, then disagreement and uncertainty will co-move". The authors note that "[...] using cross-sectional dispersion measures to proxy for uncertainty rests on the assumption that respondents draw their idiosyncratic shocks from similar distributions, so that fluctuations in dispersion are the result of fluctuations in uncertainty and not merely compositional changes in the cross-section". Importantly, "[...] business leaders [...] state that the results from the survey are an important tool in their planning process. Thus business leaders are likely to become more uncertain themselves after observing a strong increase in disagreement among peers at similar firms". In other words, when forecaster $i$ sees where his point forecast sits in the overall distribution of fellow forecasts, she might well take her own forecast and her peers' ones as signals (draws) coming from a distribution whose dispersion can therefore be approximately proxied by disagreement.

On the other hand, disagreement can be adopted as a proxy for uncertainty only to the extent it is significantly correlated with average individual uncertainty. Empirical results are mixed ${ }^{1}$, though it must be said that those studies have centered on a very limited set of variables, i.e. mainly inflation, GDP growth, and unemployment.

\subsection{Model-based uncertainty}

Some of the literature has used the volatility of actual variables as a measure of uncertainty. By this we mean anything from realized volatility, implied volatility, GARCH estimates (plus its countless variants), and cross-sectional dispersion of variables such as sales growth or stock returns from a panel of companies. Examples of this are Lehay and Whited (1996), Bloom et al. (2007), Bloom (2009), Christiano et al. (2014) and Bloom et al. (2018). However, as many factors other than uncertainty can drive fluctuations in the volatility of those variables (see Jurado et al. (2015)) one should look at the volatility of the residual variation that is obtained once all the predictable patterns are cleaned out ${ }^{2}$.

\footnotetext{
${ }^{1}$ See Bomberger and Frazer (1981), Zarnowitz and Lambros (1987), Bomberger (1996), Rich and Butler (1998), Bomberger (1999), Giordani and Söderlind (2003), D'Amico and Orphanides (2008) and Rich and Tracy (2010) on inflation uncertainty. In particular, Zarnowitz and Lambros (1987) find that disagreement understates uncertainty, but that it correlates positively with it. See Rossi B. et al. (2019) on output growth uncertainty. See Boero et al. (2008) and Lahiri and Sheng (2010) on both inflation and GDP growth uncertainty. Lahiri and Sheng (2010) actually find that disagreement is a good proxy for uncertainty, but only when the forecasting environment is stable. See Abel et al. (2016) and Rich and Tracy (2018) on inflation, output growth, and unemployment uncertainty in the Eurozone. See Diether et al. (2002) on earnings uncertainty and Bachmann et al. (2013) on business uncertainty.

${ }^{2}$ This strand of literature first started with Fernández-Villaverde and Rubio-Ramírez (2007) and Justiniano and Primiceri (2008), who estimated structural macroeconomic models with stochastic volatility and paved the way to model-based approaches for retrieving uncertainty. See also later contributions in Fernández-Villaverde and Rubio-Ramírez (2010), Fernández-Villaverde et al. (2010), Fernández-Villaverde
} 
The model can take the form

$$
y_{t}=f\left(X_{t-1}, \beta\right)+g\left(\sigma_{t}, \epsilon_{t}\right), \quad \sigma_{t}=m\left(\sigma_{t-1}, u_{t}\right), \quad \epsilon_{t}, u_{t} \stackrel{i i d}{\sim}(0,1),
$$

where $\epsilon_{t}$ is a first moment shock, and $u_{t}$ is an uncertainty shock. The literature has proposed even more general and sophisticated DGPs, but in order to give broad intuition we have preferred to report a simple though representative enough modeling choice. In particular, a popular special form of the above equation is a stochastic volatility model, where $\log \left(\sigma_{t}\right)$ evolves as an $\operatorname{AR}(1)$ process.

Importantly, the model need not be a structural model. Indeed, not only a forecasting model suffices, but given that the latter explicitly targets $\hat{y}$ instead of $\hat{\beta}$, it very likely will provide better forecasts and in turn better uncertainty measures.

There are two main concerns that can be raised with the way current model-based uncertainty measures are estimated. First, all of them are based on smoothed (as opposed to filtered) estimates of the latent volatility process. This means that any time $t(t<T)$ the uncertainty estimate will be a function of period $t+s$ information $(s=1, \ldots, T-t)$.

Second, as a consequence of using smoothed estimates, if the assumed law of motion for uncertainty is a smooth stochastic process (which is the case for stochastic volatility models where log-volatility moves as an $\mathrm{AR}(1)$ process) then the problem is potentially even greater. A simple example can help clarifying this. Let's assume a high uncertainty episode hits the economy at time $t$, and that the researcher wants to retrieve the whole time profile of uncertainty using a stochastic volatility model. As long as the researcher simply computes filtered uncertainty estimates, then the spike in uncertainty will correctly (assuming the true DGP is a stochastic volatility process) start at time $t$. However, if smoothed estimates (like those resulting from MCMC algorithms as in Kim et al. (1998)) are employed, then it is likely that the estimation process will assign a greater likelihood to uncertainty smoothly approaching a spike around period $t$, the reason being exactly that the assumed DGP is a smooth process, and that the probability of discountinuous jumps in an $\mathrm{AR}(1)$ process are very low. Therefore (and oversimplifying) when faced with the choice between an estimate that contains a discontinuous jump (i.e. the true scenario) as opposed to one where uncertainty smoothly approaches the local high level (i.e. a potentially very imprecise approximation), it is likely that the algorithm will choose the latter option, the reason being that it would entail a higher likelihood due to the assumed smooth DGP. As we will explain later, Figure 3.5 in Section 3.2 qualitatively shows that et al. (2011), Bekaert et al. (2013), Born and Pfeifer (2014), Fernández-Villaverde et al. (2015a), FernándezVillaverde et al. (2015b), Scotti (2016), Anzuini et al. (2017), Berger et al. (2017), Creal and Wu (2017) and Carriero et al. (2018) for further examples of model-based approaches. 
this issue might well be at work on actual uncertainty indexes.

This problem could be overcome by simply filtering (and not subsequently smoothing) the latent uncertainty. Since all of the stochastic processes that have been assumed for volatility are non-linear, using the Kalman Filter is not a viable option, and Sequential Monte Carlo methods such as the particle filter should be used instead ${ }^{3}$. In cases where the researcher prefers to use smoothed data, assuming a non-linear (instead of smoothed) DGP could be beneficial in order to avoid the sort of problems described in the example above. If (e.g.) the series is allowed to have discrete jumps, the "smooth pasting" issue could be solved.

Needless to say, unless the researcher is willing to re-estimate uncertainty using only data available up to the end of the training sample, model-based smoothed indexes can be used both in-sample and out-of-sample but not for pseudo-out-of-sample exercises. By contrast, filtered estimates can always be used to perform also pseudo-out-of-sample exercises.

\subsection{News-based uncertainty}

In their most common version, news-based uncertainty indexes consist (approximately) of the time series of the counts of uncertainty-related press articles. This method is theoretically less appealing but more attractive in practice. Indeed, one needs a leap of faith to believe that people talk more about uncertainty when it really is high, and viceversa. In other words, there must exist a tight and timely mapping between perceived and actual uncertainty. To address this concern, researchers usually provide event studies to show the empirical measures evolve in a sensible way.

On the other hand, news-based measures have a great appeal in practice in various situations. For instance, surveys are only available for a relatively limited set of variables, especially for probabilistic surveys. Moreover, sometimes interest is centered around uncertainty related to broad concepts (economic policy uncertainty, fiscal policy uncertainty, geopolitical risk, etc.) as opposed to well identified variables such as inflation or GDP growth. Those broader and more abstract objects are better tracked with news-based indexes. Finally, news-based indexes are model-free, and if the underlying DGP for uncertainty is highly non-linear (as it should be) chances are that a news-based index will track it better than smooth and rigid model approximations.

\footnotetext{
${ }^{3}$ Liu and West (2001) is the first contribution which allows a particle filter algorithm to jointly estimate parameters and state variables.
} 


\section{Measuring uncertainty in practice: the most popular in- dexes}

By far the most successful news-based index developed up to date is the one in Baker et al. (2016), which tracks Economic Policy Uncertainty. When their paper was first circulated as a working paper (Baker et al. (2011)) it immediately received a lot of attention. The EPU index today is used both by academics and policymakers, although from the very first days of its publication it received harsh and at times fierce criticisms ${ }^{4}$.

Baker et al. (2016) provide so-called Categorical indexes on narrower concepts of Economic Policy Uncertainty, namely Monetary Policy, Taxes, Fiscal Policy and Government Spending, Health Care, National Security, Entitlement Programs, Regulation, Financial Regulation, Trade Policy, Sovereign Debt and Currency Crises Uncertainty. Caldara and Iacoviello (2018) propose a news-based contribution that recovers Geopolitical Risk.

We devote a separate discussion to the EPU developed in Baker et al. (2016), whereas in the ensuing section we discuss the "theoretical" and empirical relationships between different uncertainty indexes.

\subsection{The EPU Index}

The US measure of EPU has been extensively discussed and validated in Baker et al. (2016). The authors convincingly show that (at least for uncertainty-related indexes) article counts make a good job in tracking underlying uncertainty. One problem that has mostly been overlooked when judging EPU indexes is that they tend to be quite noisy, meaning that high frequency movements (i.e. those that often are of interest to the policymaker) are not quite reliable.

Indeed, it seems hard to justify on a narrative ground that uncertainty really has spiked up and down violently several times in a few months, as it does happen frequently by looking at the US series. Therefore, when assessing the overall level and dynamics of uncertainty for the US, simply concentrating on the most recent observations could be misleading.

By contrast, policymakers should look at the whole time profile of the series to better assess the current position with a historical perspective. One way to do that in a more statistically sound manner is to filter the series, removing the higher frequency components, thereby leaving only ultra-low to medium-high frequency fluctuations. What "higher

\footnotetext{
${ }^{4}$ See the long debate in Krugman (2011b), Krugman (2011a), Hatzius and Stehn (2012), McKenzie (2012), Krugman (2012b), Baker et al. (2012), Krugman (2012a), Krugman (2013a), Davis (2013) and Krugman (2013b).
} 


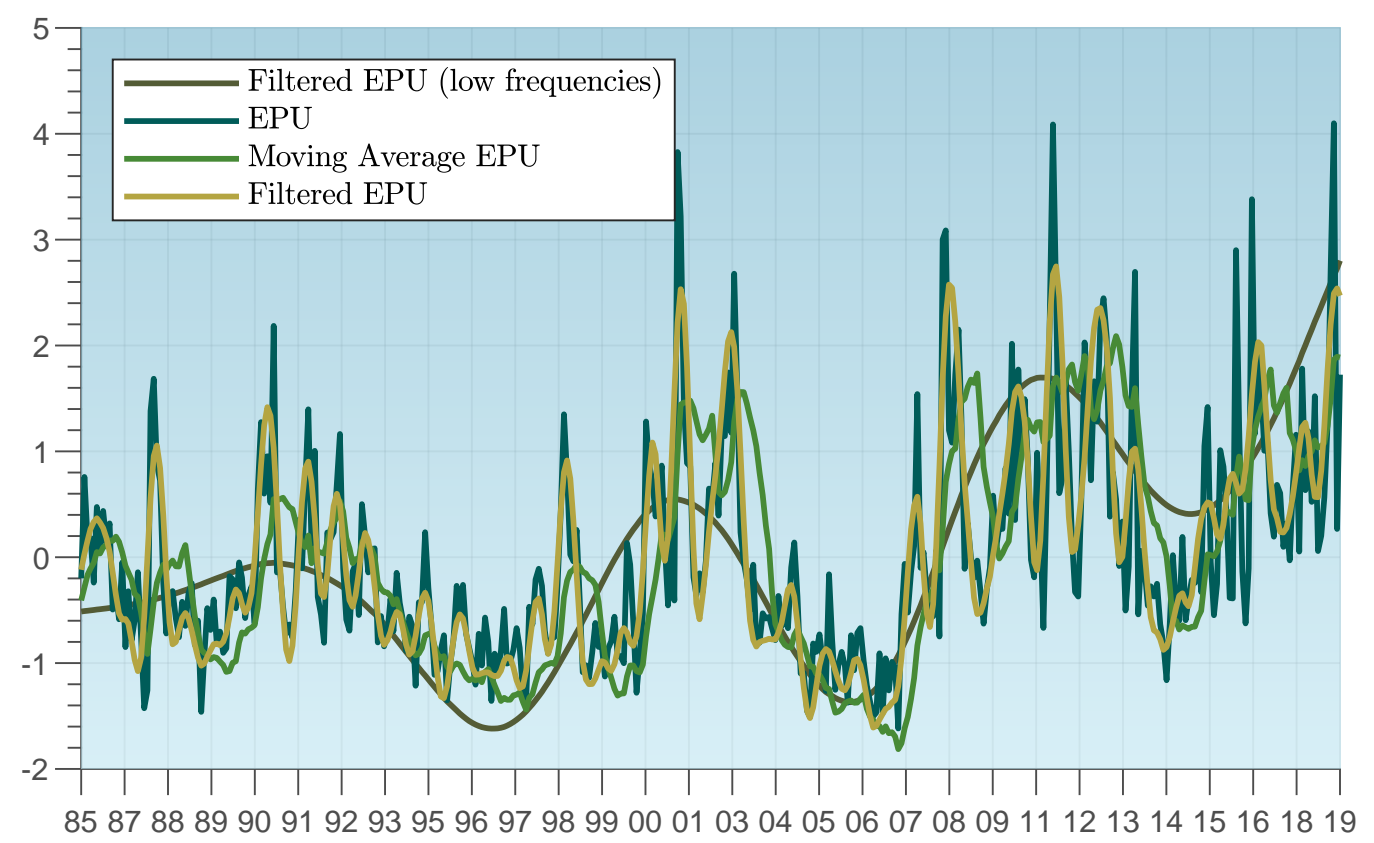

Figure 3.1: Filtered EPU for the US. The figure plots the monthly EPU index for the US against three filtered versions. The first is a 12-months moving average. The second is one where higher frequency movements up to eight months have been get rid of with the band-pass filter developed in Baxter and King (1999). The third is again a band-pass filtered series, but where only very low frequency movements have been retained. In particular, we follow Stock and Watson (1999) in defining business cycle frequencies to be those between six quarters and eight years, and retain only frequencies as low as the upper bound defined in their paper.

frequency" means in this context is of course discretional, but it seems that getting rid of movements that happen with a frequency up to eight months is enough to obtain a clearer signal. Figure 3.1 shows the original and filtered series, where it seems that the latter tells a somewhat more credible story. A twelve-months moving average is shown as well.

The last year of data (the series ends in March 2019) is a good example for our analysis. While the standard EPU series has almost gone back to its historical mean in some months (i.e. it would seem that uncertainty has been low) both the filtered series and the moving average point to a much higher (somewhere in between one and two standard deviations above the historical sample mean) and rising EPU. If we only look at the first three months of 2019 (i.e. the last three months in the series) filtered uncertainty is at its highest levels, something that is in sharp contrast with what emerges if we only look at the raw EPU series. Moreover, one can see that after the financial crisis uncertainty has been fluctuating around a significantly higher level, and this is confirmed if we only look at the very low frequency movements in Figure 3.1.

Using a frequency-domain approach is just one option. Alternatives include (as in 
Figure 3.1) filtering the series with simple moving averages, or using an online filter ${ }^{5}$. The first is very easy to implement, but at the cost of losing some of their timely information (see Figure 3.1, where the moving average significantly lags major spikes). The second option (online filter) seems to avoid this problem, depending on the assumption about the DGP of the latent uncertainty series. Finding a suitable non-linear law of motion could require a lot of search, not to mention that implementing a non-linear filter is not as easy as updating Kalman equations. To be sure, filtering the series with a band-pass filter is not free from issues. One is that it is a batch procedure, which implies that any time a new observation arrives the whole series has to be re-estimated, as opposed to an online procedure where only the most recent observation has to be estimated. In any case, our point here is not what filtering procedure is better, but simply that any sensible filtering could provide a clearer picture by better tuning the signal hidden in the series.

Note that news-based indexes such as the EPU can by their very same nature be constructed even at a daily frequency, in contrast with the other indexes where data sampling choices constrain the highest obtainable frequency. The main hurdle in achieving a meaningful daily series is to have access to a large enough bundle of news articles in order to proxy underlying uncertainty with news counts in an acceptable manner. Baker et al. (2016) do this as well by relying on the much larger Newsbank database, which comprises about 1,500 newspapers. Figure 3.2 shows that for the daily index the noisiness issue gets exacerbated, and the need to smooth the behavior of the series is unquestionable. It is ultimately an empirical question whether filtering the daily or monthly series would yield the cleanest results.

Also, results get worse once media coverage and / or the countries under consideration are smaller or simply not as central as the US. Two such examples are EPU indexes for Ireland and Sweden, respectively developed in Zalla (2017) and Armelius et al. (2017), and hosted on Baker, Bloom and Davis' uncertainty website http://www . policyuncertainty . com. Figure 3.3 shows how one can hardly see even a medium-frequency pattern in those measures, where only secular fluctuations are clear. Interestingly, while Ireland's EPU index is based on a single newspaper (which surely is a key driving factor in yielding

\footnotetext{
${ }^{5}$ Both the Kalman Filter and more sophisticated methods such as Sequential Monte Carlo (SMC) algorithms are generally called online filters in the signal processing literature, the reason being that estimation of the latent variable is performed recursively as new data arrives. On the other hand, offline (or batch) procedures such as MCMC algorithms estimate any time $t$ latent variable realization using all the available data, not just those available up to time $t$. The intuition behind SMC methods is the very same as the one underlying the Kalman Filter; what differs is the mechanics used to estimate the variables. This is so because, as opposed to the Kalman Filter, SMC methods have been developed especially to retrieve nonlinear latent time series, and given that closed-form solutions are not available to estimate those processes, simulation from the predictive and filtering densities has to be used instead.
} 


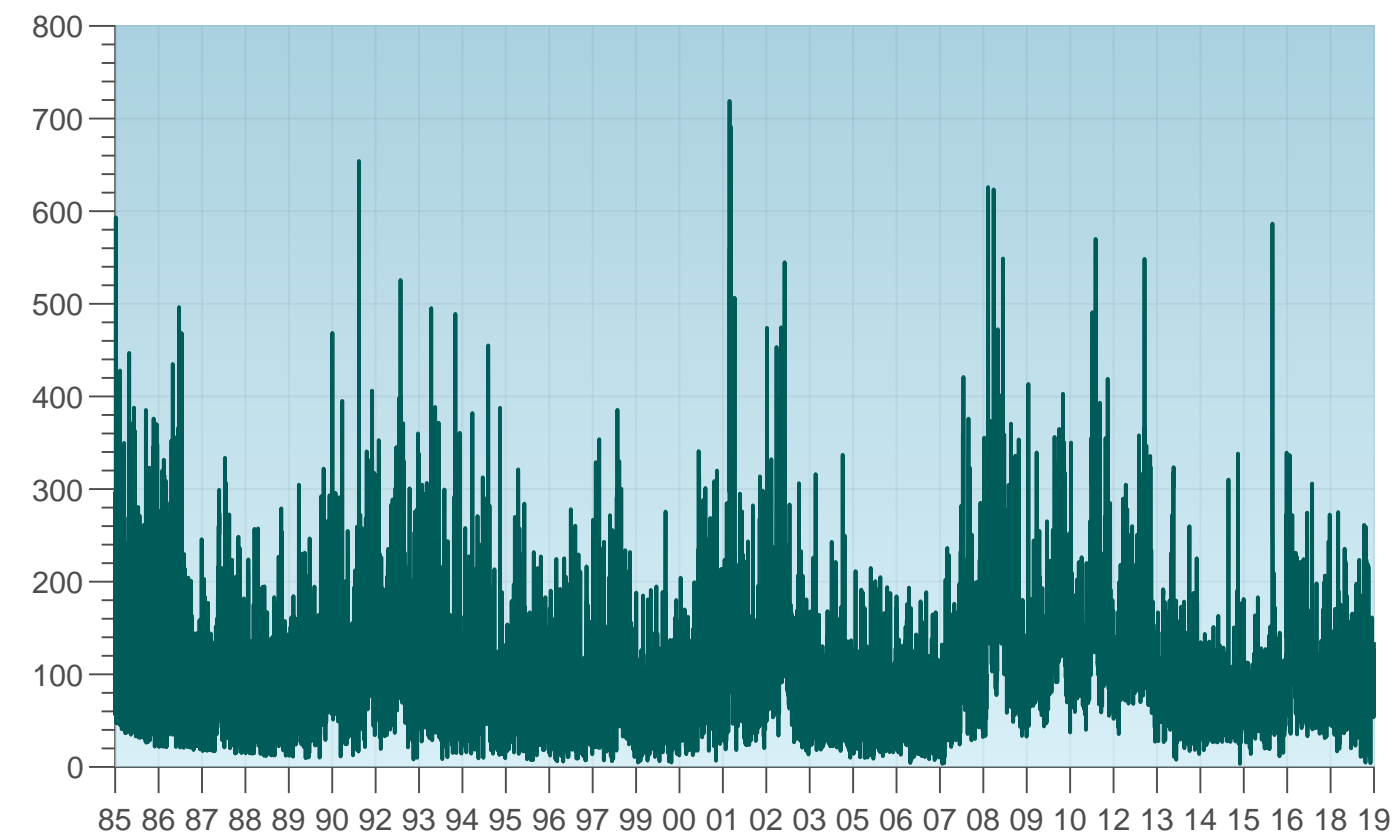

Figure 3.2: Daily EPU for the US. The figure plots the daily EPU index for the US. Apparently, the cost of obtaining a higher-frequency series is that measurement errors of latent uncertainty are arguably wider.

the highly noisy series) Sweden's EPU index uses four newspapers, so one could ex-ante expect to see a somehow clearer signal. While to some extent this seems to be the case, the time profile is still very noisy, and the fact that Sweden is a small economy might be one reason for this. Indeed, what happens in Sweden has far smaller consequences for the rest of the world than is the case for the US, and this (ceteris paribus) might be reflected in a lower media coverage.

Apart from this issue, one might genuinely ask why the measure by Baker et al. (2016) has achieved such popularity and what ingredients made it so successful. We attempt to give an answer. First, the EPU (and its related neighbors) is extremely intuitive, easy to compute, and transparent, meaning there are no obscure details that could cast doubts on the machinery behind the index. Second, and related to this, it is a model-free index with very few degrees of freedom. The set of words and their logical interactions are the obvious control variable, but the EPU is built with a very reasonable and small bundle of words. Third, it is a real-time measure and being immutable over time it does not depend on any data vintage, something which is very desirable from a policymaker perspective. Fourth, it relies on one single key assumption, i.e. that the large community of journalists and pundits on aggregate (i.e. not necessarily individually) talk proportionally and consistently more about uncertainty exactly when it is proportionally higher, and viceversa. 

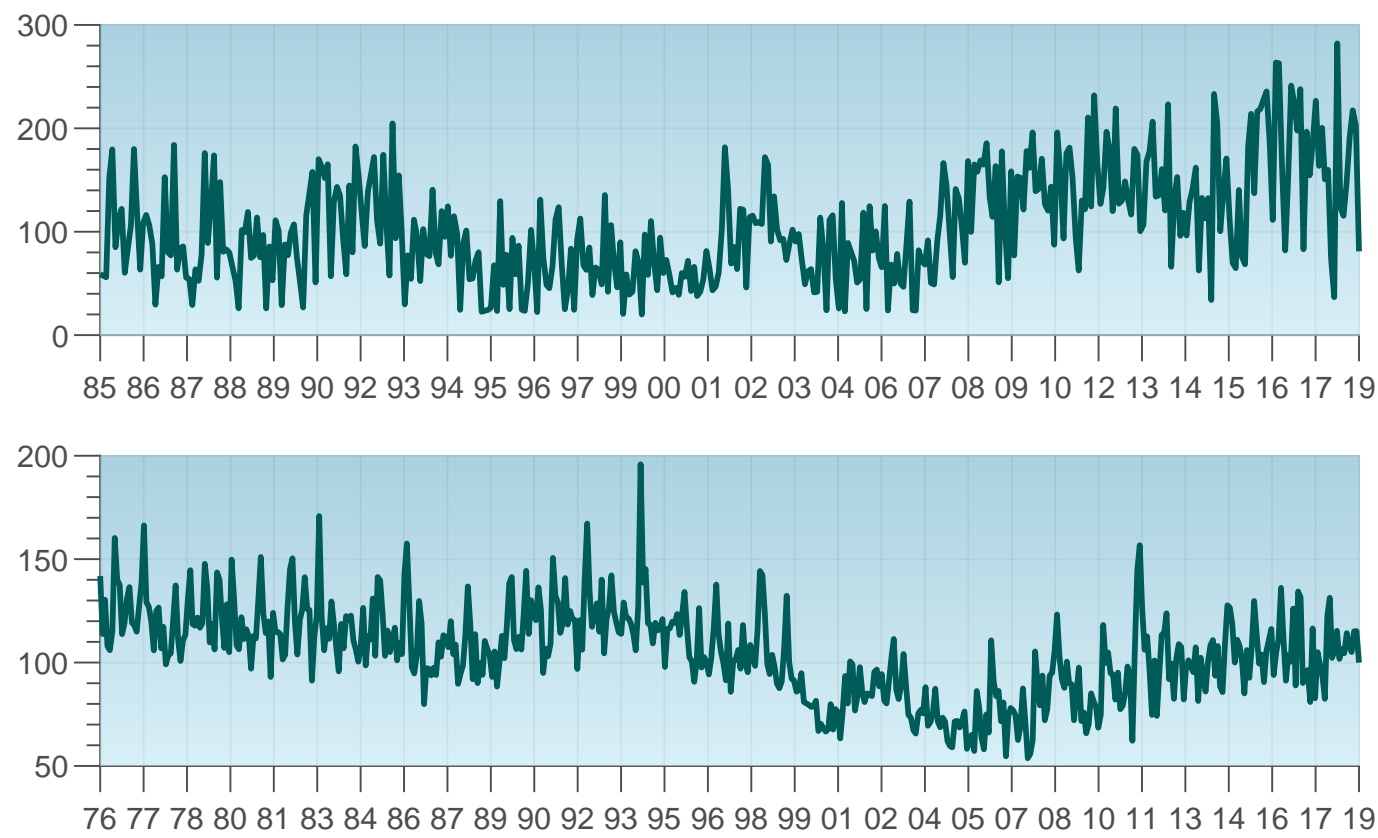

Figure 3.3: EPU indexes for Ireland and Sweden. The upper panel plots the EPU index for Ireland, whereas the lower panel shows the EPU index for Sweden. As compared to the US series, the signal-tonoise ratio in those cases is significantly lower.

Fifth (and only as what regards the US and the UK) there exists a version which dates back until 1900. This version relies on a smaller set of newspapers, i.e. six and two for the US and the UK respectively. No other index goes so far back in time ${ }^{6}$. Finally, many countries do not have obvious "second-moment" measures (as the VIX for the US) so that news-based indexes work as welcome substitutes for those countries.

\subsection{The relationship between different uncertainty measures}

In this section we briefly compare the Economic Policy Uncertainty (EPU) index in Baker et al. (2016) and the model-based Macroeconomic Uncertainty index (henceforth JLN) in Jurado et al. (2015), and we show them along with the VIX. Although the VIX is an implied volatility and not an uncertainty measure ${ }^{7}$, we plot it here as well in view of its widespread use as a benchmark "fear index". Although we are admittedly comparing indexes that track different concepts of uncertainty, we believe it is still worth to see them

\footnotetext{
${ }^{6}$ By comparison, the VIX starts in February 1990, the VXO starts in January 1986, Jurado et al. (2015) Macroeconomic and Financial Uncertainty index starts in July 1960, Rossi B. et al. (2019) Business Cycle Uncertainty index starts in 1982Q3.

${ }^{7}$ See discussion in Jurado et al. (2015).
} 
together in order to better understand their empirical features, differences and similarities.

While we already discussed EPU in Section 3.1, and given that the VIX is already widely known and understood, we are still left with explaining some details about how JLN is constructed before talking about the relationships between those indexes.

Jurado et al. (2015) use a large monthly panel of $N$ financial and economic time series and fit $N$ FAVAR models where the $i$-th variable conditional mean depends on autoregressive terms and lagged common factors, and the $(\log )$ conditional volatilities of both the variables and the common factors are assumed to evolve as an autoregressive process, a set-up commonly known as a stochastic volatility model. The FAVARs are estimated with OLS, whereas the uncertainty series are computed from forecast error variance decompositions of OLS residuals using MCMC algorithms. The preferred uncertainty measure is then the arithmetic average of all the $N$ forecast error variance estimates. The authors retrieve three measures relating to Macroeconomic, Real, and Financial uncertainty by using different sets of variables, although the basic procedure is always the same ${ }^{8}$. Uncertainty is estimated with an iterated forecast approach, meaning that the dependent variable appears with a one-month-ahead horizon, and parameters are iterated forward to obtain further three- and twelve-months-ahead uncertainty measures. Here we will only focus on the one-month-ahead Macroeconomic Uncertainty measure.

Figure 3.4 shows the three measures of uncertainty and volatility ${ }^{9}$. One can see that the very low-frequency movements are largely the same, and that JLN is much smoother than both the EPU and the VIX. This last feature is understandable given how those indexes are constructed, since JLN impose some time structure on the evolution of the index, where EPU/VIX do not. The noisiness issue in the EPU (as discussed in Section 3.1) is clearly visible in the figure, where one can see that even the VIX seems to behave in a less chaotic way. However, most of the major spikes in the VIX also appear in EPU, and with the same (or almost the same) timing.

Figure 3.5 is meant to show the problem we highlighted in Section 2.2, i.e. that modelbased uncertainty measures like JLN tend to oversmooth highly non-linear events such as the 2008 financial crisis. Indeed, while (as we said) model-free indexes like the EPU and the VIX approximate this nonlinearity better, JLN starts a gradual upward path much earlier, approximately starting in the second quarter of 2008, and decay with a similarly slow pace after the most turbulent events have been absorbed by the markets and the

\footnotetext{
${ }^{8}$ Macroeconomic Uncertainty is the weighted average of uncertainty regarding real variables (which indeed is called Real Uncertainty) and uncertainty related to nominal ones.

${ }^{9}$ Sample correlation between (i) the EPU and JLN is $25.9 \%$; (ii) the EPU and the VIX is $40.9 \%$; (iii) JLN and the VIX is $62.5 \%$.
} 


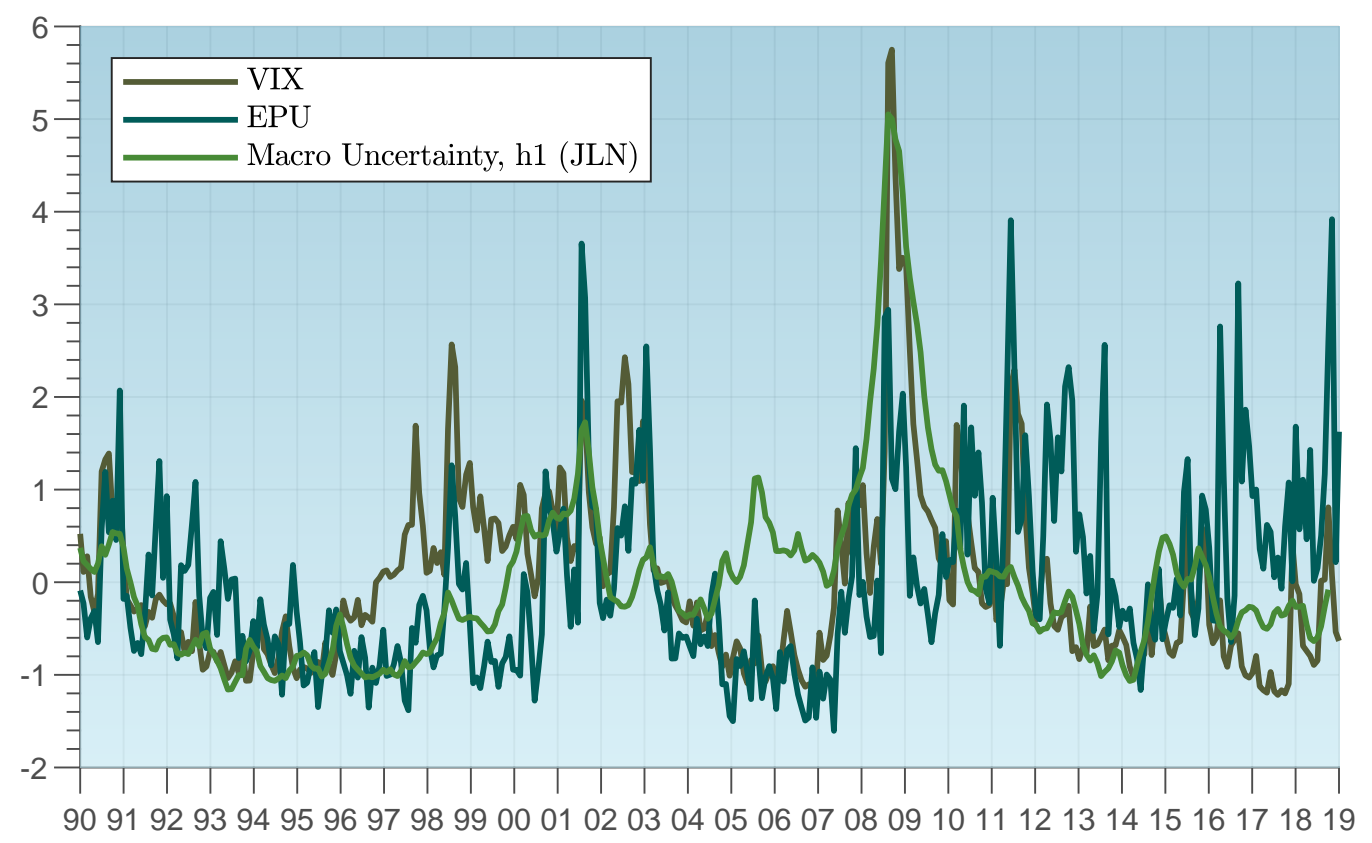

Figure 3.4: Different uncertainty measures. The figure plots three uncertainty measures obtained with very different methodologies: the news-based EPU index from Baker et al. (2016), the model-based onemonth-ahead Macro Uncertainty index from Jurado et al. (2015), and implied volatility as represented by the VIX.

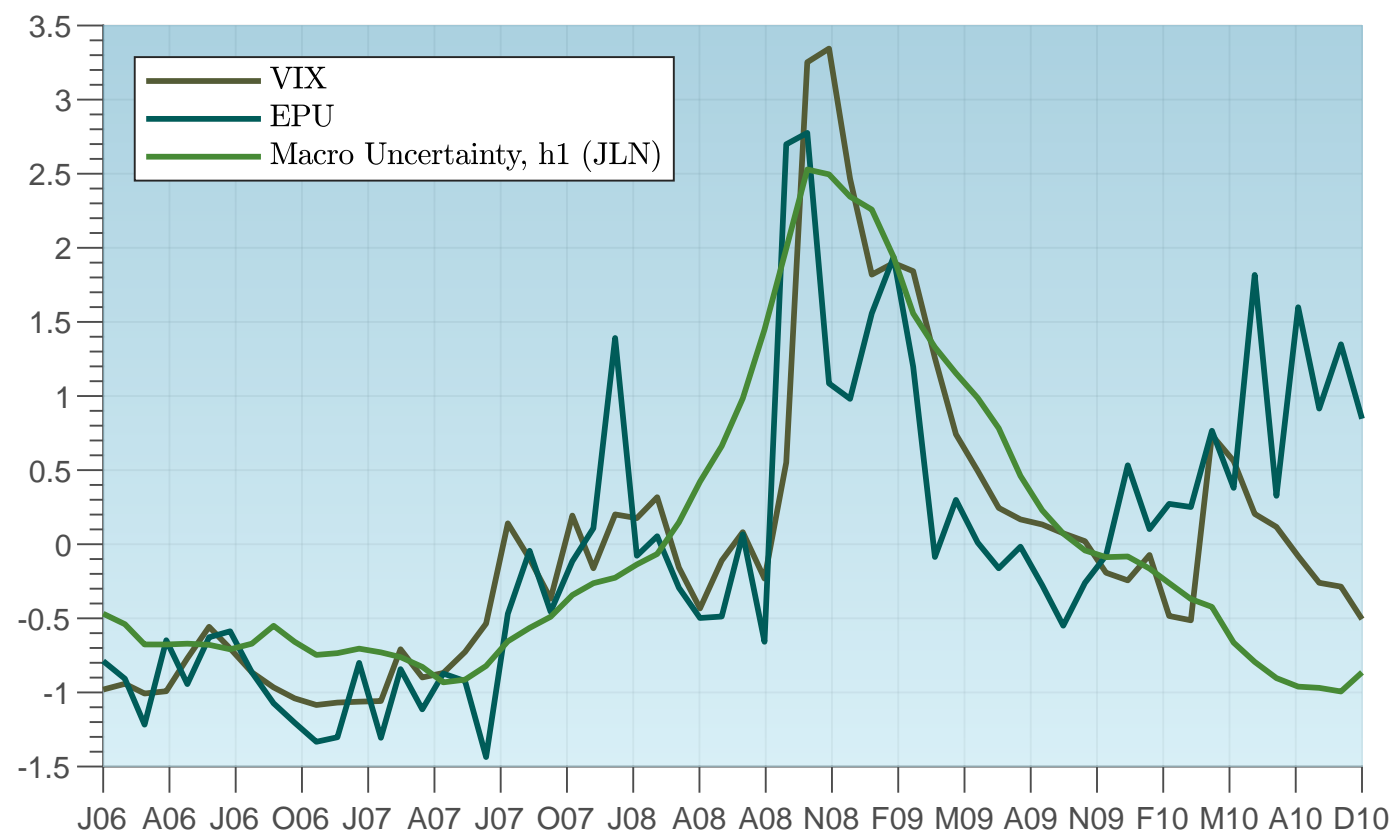

Figure 3.5: Different uncertainty measures, a zoom on the financial crisis. The figure plots the same series as in Figure 3.4, but we zoom onto the 2008 financial crisis to better assess the different behavior of different uncertainty indexes. 
news.

Finally, as Rossi B. et al. (2019) put it:"[...] It seems that Baker et al. (2016) uncertainty measure is driven more by ex-ante uncertainty, while the Jurado et al. (2015) uncertainty measure is clearly affected by ex-post uncertainty, namely uncertainty due to misspecification in the predictions". We add that the smooth DGP assumption for log-volatility might play a role as well, and that the fact that JLN captures ex-post uncertainty is no mistake, the reason being that uncertainty in JLN is higher exactly when the realized value for the variable at hand is significantly higher (or lower) than what might have been expected on the basis of the estimated forecasting model.

\section{Novel contributions with US Data}

This section briefly discusses some new policy and academic contributions. Since they either are "work in progress" or are based on too short samples to allow a full evaluation of their properties, we discuss them in a separate section. Nevertheless, they look into special aspects of uncertainty and to related (although different) measures, so we believe it is worth briefly discussing them in order to provide a broader view of the topic.

\subsection{Atlanta Fed - Chicago Booth - Stanford University Survey of Busi- ness Uncertainty}

The joint Atlanta Fed/Chicago Booth/Stanford University Survey of Business Uncertainty (SBU) is monthly and relies on 1200 representative panel members with senior finance and managerial positions at US companies. The Survey targets subjective probability distributions over own-firm one-year-ahead growth rates in future sales, employment levels, average unit cost growth, and capital investment expenditures.

The first SBU was administered in July 2014, and synthetic indexes are available online since January 2015 on the Atlanta Fed website. The average response rate is about $43 \%$, and the response time averages five minutes. In order to reduce the cognitive burden and obtain more precise answers, but also to have a survey that is wide in scope, SBU developers randomly send only one of two questionnaires every month to each member, so that about half of the respondents receive the so-called SE questionnaire (with questions about sales revenue and number of employees) and half receive the CC questionnaire (with questions about unit costs and capital expenditures).

The first results are based on the October 2014 - August 2018 period only, so care must be taken in drawing conclusions from them. Nevertheless, some interesting patterns seem 
to emerge. In particular, firms' subjective expectations are highly predictive of realized outcomes, and firms' subjective uncertainty is highly predictive of the magnitude of expost forecast errors.

Importantly, the authors use the SBU to construct a monthly activity-weighted expectations (first-moment) and uncertainty (second-moment) index for employment, sales, capital expenditures, and average unit costs growth rates. Again, there is preliminary evidence that the Business Expectations Index comoves with Industrial Production growth, while the Business Uncertainty Index comoves with the VIX. The way the uncertainty index is built strongly resembles what Guiso and Parigi (1999) do, where the authors construct their measure from the Company Accounts Data Service database and the Survey on Investment in Manufacturing conducted by the Bank of Italy, where approximately 1000 Italian firms are asked for their subjective probability distributions of future demand for their own products.

Thanks to the theoretically-grounded way the SBU is developed and to the large panel it uses, the Business Uncertainty Index has great potential to become one of the benchmark US uncertainty measures, even though time is needed to be able to have a longer historical comparison. For further details, see Altig et al. (2018).

\subsection{Equity Market Volatility Tracker}

Baker et al. (2019) depart from the uncertainty literature and focus on volatility. The paper again exploits newspapers to develop a so-called Equity Market Volatility Tracker (EMV) which is expliticly built to mimick the VIX. The reason why this should be interesting in the first place is that while the VIX only gives a gauge of the overall market implied volatility as derived from option prices, the EMV can be disaggregated by topic relevance in order to understand what sources drive volatility at every point in time, something researchers have been asking for a long time.

The EMV is built by first defining three sets of words, each directly relating to the initial letters of the three E-M-V words. Then, an algorithm looks for the combination of words that yields the index which comoves the most with the VIX, using data from 1990 to 2015. The selected index correlates $80 \%$ with the VIX, where this very high value obviously has to be taken with a grain of salt given that the index explicitly maximizes in-sample this correlation, as opposed to the other measures we have discussed so far.

In general, the main finding is that policy concerns have shown a growing importance in driving volatility, and this trend does not appear to show signs of reversal. Moreover, Monetary Policy and Tax Policy are the most important policy-related sources of stock 
market volatility.

\subsection{Sentiment-based Indexes of Financial Stress}

A further research avenue that is gaining popularity is the one that measures financial stress. Although "stress" is not a useful statistical concept, its measurement is usually obviously related to second moments, although it would make sense to link it to third moments too (i.e. measures of skewness).

Püttman (2018) looks into newspapers since the end of the nineteenth century to single out a sentiment-based index of financial stress (FSI). Once again, this is not the only such index, but we will focus on it for illustrative purposes ${ }^{10}$.

The index is computed in various steps. First, only articles discussing financial issues are retained from the universe of articles. This first step checks whether the title of each article contains words from the author-made 120-word financial dictionary, and discards all those articles that do not meet this condition. Second, logical conditions decide whether the title of the article (not the content) has an overall positive, neutral, or negative tone. This step uses four research-based dictionaries that assign a positive or negative tone to each unigram (i.e. individual word). If the title of the article contains more (less) negative than positive words the overall sentiment of the article is counted as negative (positive). If the number of negative words equals the number of positive ones, the article is counted as neutral. The final Financial Stress Index averages counts over dictionaries and newspapers to obtain the final series.

It is noteworthy that Püttman (2018) only has access to titles, not the whole content of the articles. While this would clearly appear as a drawback, the author provides a counterargument whereby looking only at titles allows to search for broader lists of words than is the case for the full article content.

As the paper shows, the FSI correlates strongly with the VIX (74\%). This is notable, because as opposed to Baker et al. (2019) who target this correlation by maximizing it, Püttman (2018) uses an independent, simple and transparent procedure, and obtains a very high correlation as well. The time series profile of the FSI indeed very closely replicates the VIX, with only minor differences. However, while in Baker et al. (2019) the authors are able to disaggregate their EMV index in order to infer what drives stock market volatility at each point in time, here no clear disaggregation has been performed yet.

\footnotetext{
${ }^{10}$ See references in Püttman (2018) for further contributions. Also, Prometeia recently developed a new sentiment-based index for Italy, but the company provides no documentation whatsoever, so that a formal assessment of the index is not possible.
} 


\subsection{Fiscal Policy Uncertainty}

Anzuini and Rossi L. (2018) provide a survey-based measure of Fiscal Policy Uncertainty for the US. The index is constructed from Federal Budget Net Lending forecasts in Consensus Economics, and merges them with the Philadelphia Fed Survey of Professional Forecasters in order to obtain a monthly index of Fiscal Policy Uncertainty (FPU-AR).

As is well known, Consensus Economics only provides point forecasts for each of the variables covered in the survey. Therefore, the only measure of uncertainty that one can compute is necessarily based on disagreement. Section 2.1 showed that evidence on the appropriateness of the cross sectional dispersion as a measure of uncertainty is mixed. Therefore, we provide here evidence that at least for what concerns US Fiscal Policy Uncertainty, the disagreement-based FPU index in Anzuini and Rossi L. (2018) proxies well the underlying uncertainty.

In order to show this, and given that to the best of our knowledge no probabilistic survey about the US federal budget exists (which prevents us from constructing average individual uncertainty measures) we compare the FPU-AR measure with the Baker et al. (2016) Categorical FPU Index (FPU-BBD). Fernández-Villaverde et al. (2015a) also develop a model-based FPU measure for the US, but their index is based on average capital tax rates, a much narrower concept that does not include the vast majority of decisions concerning fiscal policy.

Figure 4.1 displays the two FPU measures against each other. Since (as highlighted in Alizadeh et al. (2002) for stock market volatility) volatility measures tend to more closely resemble log-normal distributions than normal ones, we take logs of our FPU instead which (unlike BBD) is computed as a sample standard deviation and therefore analogous to a volatility measure. The correlation between the two series is $49 \%$, and one can see from the broad pattern that the two measures move very closely to each other, although the news-based measure is much more volatile, especially in the years of the debt ceiling dispute, the fiscal cliff, and the European sovereign debt crisis. Interestingly, both measures spike violently exactly after Donald Trump is elected US President.

Finally, for the FPU-AR measure we find the same result as the one found in Zarnowitz and Lambros (1987) for inflation, namely that (in the FPU case) high expectations about the Federal Budget deficit (or surplus) are associated with higher uncertainty about the same variable. In our view, the intuition is that it is simply harder to forecast the deficit when it is expected to stay at (e.g.) $7-8 \%$ of GDP (a level unlikely to be regarded as sustainable in the medium term) than when it is expected to be on balance. 


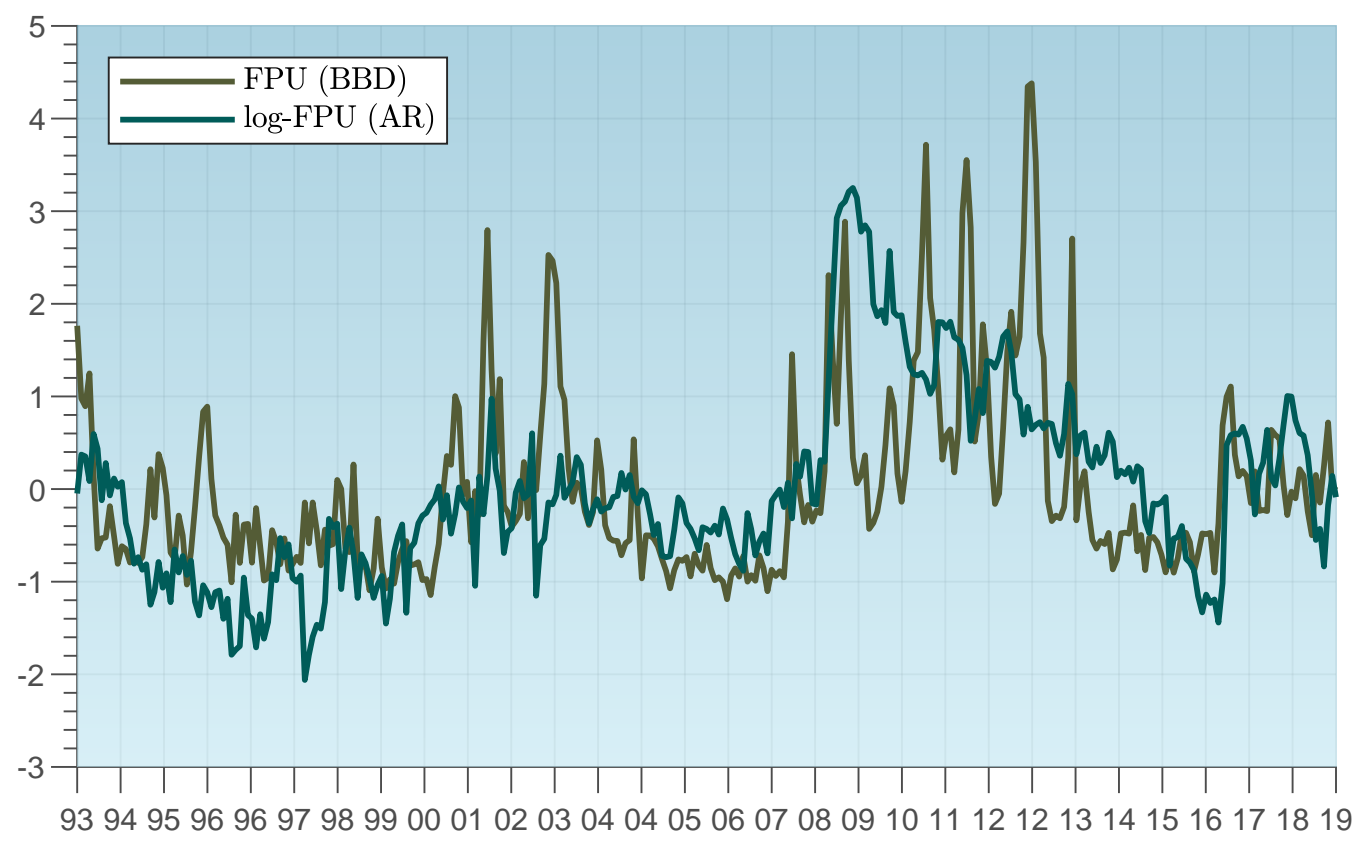

Figure 4.1: US Fiscal Policy Uncertainty. The figure shows Anzuini and Rossi L. (2018) survey-based log-FPU against Baker et al. (2016) news-based FPU.

\section{Concluding remarks}

In this note we have provided an overview of the state of the art in the measurement of uncertainty by briefly explaining the main methodologies put forward up to now and discussing some of the most popular uncertainty indexes.

As we have seen, each method has its pros and cons, but revealed preferences inferred from policy discussions and academic papers undoubtedly show that news-based indexes and, in particular, those developed in Baker et al. (2016) are the ones that have gained the most attention. We discussed what we think are the reasons for this: their intuitiveness, transparency and real-time characteristics are those that have attracted people to focus on news counts.

Having said that, we identified what we think is the main problem with news indexes as they are constructed today, namely their noisiness. We show that this issue is likely to be exacerbated for measures that rely on only a few newspapers, but also when the country is small and not very central in the global economic and financial network. We thus suggest that, for policy purposes, it would be better to disregard very high frequency movements in the series, which could well provide a misleading inference on the actual level of uncertainty. For researchers, combining news counts with online filters appears 
to be a worthwhile avenue for research, which could help mitigate the measurement error in news indexes while maintaining their real-time feature, something that would be impossible to do using batch procedures such as band-pass filters.

For the very same reason, using filtered as opposed to smoothed estimates in modelbased uncertainty measures would be beneficial also for policy purposes. Finally, welldeveloped surveys still represent a hard-to-beat benchmark when one is interested in uncertainty around specific variables as opposed to more abstract concepts such as Economic Policy Uncertainty and the like. In this respect, the new Survey of Business Uncertainty jointly developed by the Atlanta Fed, Chicago Booth School of Business, and Stanford University has all that it takes to become a very useful business uncertainty tracker for the US. 


\section{References}

Abel, J., Rich, R., Song, J., Tracy, J., April 2016. The Measurement and Behavior of Uncertainty: Evidence from the ECB Survey of Professional Forecasters. Journal of Applied Econometrics 31 (3), 533-550.

Alizadeh, S., Brandt, M. W., Diebold, F. X., 2002. Range-Based Estimation of Stochastic Volatility Models. Journal of Finance 57 (3), 1047-1091.

Altig, D., Barrero, J. M., Bloom, N., Bryan, M., Davis, S. J., Meyer, B. H., Parker, N., 2018. Survey of Business Uncertainty. Tech. rep.

Anzuini, A., Rossi, L., Tommasino, P., 2017. Fiscal policy uncertainty and the business cycle: time series evidence from Italy. Temi di Discussione (Economic Working Papers) (1151).

Anzuini, A., Rossi L., L., 2018. Fiscal policy in the US: a new measure of uncertainty and its recent development. Temi di Discussione (Economic Working Papers) (1197).

Armelius, H., Hull, I., Stenbacka Köhler, H., 2017. The timing of uncertainty shocks in a small open economy. Economics Letters 155 (C), 31-34.

Bachmann, R., Elstner, S., Sims, E. R., April 2013. Uncertainty and Economic Activity: Evidence from Business Survey Data. American Economic Journal: Macroeconomics 5 (2), 217-249.

Baker, S. R., Bloom, N., Davis, S. J., 2011. Measuring Economic Policy Uncertainty. Mimeo.

Baker, S. R., Bloom, N., Davis, S. J., 2016. Measuring Economic Policy Uncertainty. The Quarterly Journal of Economics 131 (4), 1593-1636.

Baker, S. R., Bloom, N., Davis, S. J., Kost, K. J., 2019. Policy News and Stock Market Volatility. NBER Working Papers (25720).

Baker, S. R., Bloom, N., Davis, S. J., Reenen, J. V., October 29 ${ }^{\text {th }}$, 2012. Economic Recovery and Policy Uncertainty in the US. VoxEu.

URL https://voxeu.org/article/economic-recovery-and-policy-uncertainty-us

Baxter, M., King, R. G., 1999. Measuring Business Cycles: Approximate Band-Pass Filters For Economic Time Series. The Review of Economics and Statistics 81 (4), 575-593. 
Bekaert, G., Hoerova, M., Lo Duca, M., 2013. Risk, uncertainty and monetary policy. Journal of Monetary Economics 60 (7), 771-788.

Berger, T., Grabert, S., Kempa, B., 2017. Global macroeconomic uncertainty. Journal of Macroeconomics 53 (C), 42-56.

Bloom, N., 2009. The Impact of Uncertainty Shocks. Econometrica 77 (3), 623-685.

Bloom, N., 2014. Fluctuations in Uncertainty. Journal of Economic Perspectives 28 (2), 153-176.

Bloom, N., Bond, S., Reenen, J. V., 2007. Uncertainty and Investment Dynamics. Review of Economic Studies 74 (2), 391-415.

Bloom, N., Floetotto, M., Jaimovich, N., Eksten, I. S., Terry, S. J., May 2018. Really Uncertain Business Cycles. Econometrica 86 (3), 1031-1065.

Boero, G., Smith, J., Wallis, K. F., 2008. Uncertainty and Disagreement in Economic Prediction: The Bank of England Survey of External Forecasters. The Economic Journal 118, $1107-1127$.

Bomberger, W. A., 1996. Disagreement as A Measure of Uncertainty. Journal of Money, Credit and Banking 28 (3), 381-392.

Bomberger, W. A., 1999. Disagreement and Uncertainty: A Reply to Rich and Butler. Journal of Money, Credit and Banking 31 (2), 273-276.

Bomberger, W. A., Frazer, W. J., 1981. Interest Rates, Uncertainty, and the Livingston Data. Journal of Finance 36 (3), 661-675.

Born, B., Pfeifer, J., 2014. Policy risk and the business cycle. Journal of Monetary Economics $68(\mathrm{C}), 68-85$.

Caldara, D., Iacoviello, M., Feb. 2018. Measuring Geopolitical Risk. International Finance Discussion Papers 1222, Board of Governors of the Federal Reserve System (U.S.).

Carriero, A., Clark, T. E., Marcellino, M., 2018. Measuring Uncertainty and Its Impact on the Economy. The Review of Economics and Statistics 100 (5), 799-815.

Christiano, L. J., Motto, R., Rostagno, M., 2014. Risk Shocks. American Economic Review $104(1), 27-65$. 
Creal, D. D., Wu, J. C., November 2017. Monetary Policy Uncertainty And Economic Fluctuations. International Economic Review 58 (4), 1317-1354.

D'Amico, S., Orphanides, A., 2008. Uncertainty and disagreement in economic forecasting. Tech. rep.

Davis, S. J., August $12^{\text {th }}$, 2013. Straw Man Bites the Dust: A Response to Paul Krugman on Policy Uncertainty. Capital Ideas Blog, Chicago Booth School of Business.

Diether, K. B., Malloy, C. J., Scherbina, A., October 2002. Differences of Opinion and the Cross Section of Stock Returns. Journal of Finance 57 (5), 2113-2141.

Fernández-Villaverde, J., Guerrón-Quintana, P., Kuester, K., Rubio-Ramírez, J., 2015a. Fiscal Volatility Shocks and Economic Activity. American Economic Review 105 (11), 33523384 .

Fernández-Villaverde, J., Guerrón-Quintana, P., Rubio-Ramírez, J. F., Apr. 2010. Fortune or Virtue: Time-Variant Volatilities Versus Parameter Drifting in U.S. Data. NBER Working Papers 15928, National Bureau of Economic Research, Inc.

Fernández-Villaverde, J., Guerrón-Quintana, P., Rubio-Ramírez, J. F., 2015b. Estimating dynamic equilibrium models with stochastic volatility. Journal of Econometrics 185 (1), 216-229.

Fernández-Villaverde, J., Guerrón-Quintana, P., Rubio-Ramírez, J. F., Uribe, M., October 2011. Risk Matters: The Real Effects of Volatility Shocks. American Economic Review 101 (6), 2530-2561.

URL https://ideas.repec.org/a/aea/aecrev/v101y2011i6p2530-61.html

Fernández-Villaverde, J., Rubio-Ramírez, J., Dec. 2010. Macroeconomics and Volatility: Data, Models, and Estimation. NBER Working Papers 16618, National Bureau of Economic Research, Inc.

Fernández-Villaverde, J., Rubio-Ramírez, J. F., 2007. Estimating Macroeconomic Models: A Likelihood Approach. Review of Economic Studies 74 (4), 1059-1087.

Giordani, P., Söderlind, P., December 2003. Inflation forecast uncertainty. European Economic Review 47 (6), 1037-1059.

Guiso, L., Parigi, G., 1999. Investment and Demand Uncertainty. The Quarterly Journal of Economics 114 (1), 185-227. 
Hatzius, J., Stehn, J., October 19 ${ }^{\text {th }}$, 2012. Policy Uncertainty: is Now the Time? Goldman Sachs Economic Research 12 (42).

Jurado, K., Ludvigson, S. C., Ng, S., March 2015. Measuring Uncertainty. American Economic Review 105 (3), 1177-1216.

Justiniano, A., Primiceri, G. E., June 2008. The Time-Varying Volatility of Macroeconomic Fluctuations. American Economic Review 98 (3), 604-641.

Kim, S., Shephard, N., Chib, S., 1998. Stochastic Volatility: Likelihood Inference and Comparison with ARCH Models. Review of Economic Studies 65 (3), 361-393.

Krugman, P., December $7^{\text {th }}, 2011$ a. Taylor Rules. The New York Times.

URL https ://krugman . blogs .nytimes . com/2011/12/07/taylor-rules/

Krugman, P., October $13^{\text {th }}, 2011 \mathrm{~b}$. Varieties of Uncertainty. The New York Times.

URL

https://krugman.blogs .nytimes . com/2011/10/13/

varieties-of-uncertainty/

Krugman, P., October 31 ${ }^{\text {st }}$, 2012a. Asymmetrical "Uncertainty". The New York Times.

URL https://krugman . blogs .nytimes . com/2012/10/31/ asymmetrical-uncertainty/?mtrref=www . google. com\&gwh= CD7713A36CF8A952CDEA434279132356\&gwt=pay

Krugman, P., October 22 ${ }^{\text {nd }}, 2012 \mathrm{~b}$. The "Uncertainty" Scam. The New York Times. URL https://krugman.blogs.nytimes.com/2012/10/22/the-uncertainty-scam/ ?mtrref=www google. com\&gwh=B1E5625EFD0F378E5DCDC340FCA032B6\&gwt=pay

Krugman, P., August $8^{\text {th }}, 2013 \mathrm{a}$. Phony Fear Factor. The New York Times. URL https://www.nytimes.com/2013/08/09/opinion/krugman-phony-fear-factor . html

Krugman, P., October $1^{\text {st }}, 2013 \mathrm{~b}$. What They Say versus What They Mean. The New York Times.

URL https://krugman.blogs.nytimes.com/2013/10/01/ what-they-say-versus-what-they-mean/

Lahiri, K., Sheng, X., 2010. Measuring Forecast Uncertainty by Disagreement the Missing Link. Journal of Applied Econometrics 25 (4), 514-538.

Lehay, J. V., Whited, T. M., 1996. The Effect of Uncertainty on Investment Some Stylized Facts. Journal of Money, Credit and Banking 28 (1), 64-83. 
Liu, J., West, M., 2001. Combined Parameter and State Estimation in Simulation-Based Filtering, in Doucet, A., de Freitas, N., and Gordon, N. (eds), Sequential Monte Carlo Methods in Practice, Springer-Verlag, New York.

McKenzie, K., October $22^{\text {nd }}$, 2012. Is 'uncertainty' really that big a deal? Financial Times Alphaville.

URL https://ftalphaville.ft.com/2012/10/22/1222541/ is-uncertainty-really-that-big-of-deal/

Püttman, L., 2018. Patterns of Panic: Financial Crisis Language in Historical Newspapers. Mimeo.

Rich, R. W., Butler, J., 1998. Disagreement as A Measure of Uncertainty: A Comment on Bomberger. Journal of Money, Credit and Banking 30 (3), 411-419.

Rich, R. W., Tracy, J., 2010. The Relationships Among Expected Inflation, Disagreement, and Uncertainty: Evidence from Matched Point and Density Forecasts. The Review of Economics and Statistics 92 (1), 200-207.

Rich, R. W., Tracy, J., Jul. 2018. A Closer Look at the Behavior of Uncertainty and Disagreement: Micro Evidence from the Euro Area. Working Papers 1811, Federal Reserve Bank of Dallas.

Rossi B., B., Sekhposyan, T., May 2015. Macroeconomic Uncertainty Indices Based on Nowcast and Forecast Error Distributions. American Economic Review 105 (5), 650655.

Rossi B., B., Sekhposyan, T., August 2017. Macroeconomic uncertainty indices for the Euro Area and its individual member countries. Empirical Economics 53 (1), 41-62.

Rossi B., B., Sekhposyan, T., Soupre, M., 2019. Understanding the Sources of Macroeconomic Uncertainty. Mimeo.

Scotti, C., 2016. Surprise and uncertainty indexes: Real-time aggregation of real-activity macro-surprises. Journal of Monetary Economics 82 (C), 1-19.

Stock, J. H., Watson, M. W., 1999. Business cycle fluctuations in us macroeconomic time series. In: Taylor, J. B., Woodford, M. (Eds.), Handbook of Macroeconomics. Vol. 1 of Handbook of Macroeconomics. Elsevier, Ch. 1, pp. 3-64.

Zalla, R., 2017. Economic Policy Uncertainty in Ireland. Atlantic Economic Journal 45, 269-271. 
Zarnowitz, V., Lambros, L. A., 1987. Consensus and Uncertainty in Economic Prediction. Journal of Political Economy 95 (3), 591-621. 